\title{
Interaction between the RGS6 gene and psychosocial stress on obesity-related traits
}

\author{
Hyun-Jin Kim ${ }^{1)}$, Jin-young Min ${ }^{1)}$ and Kyoung-bok Min²) \\ 1) Institute of Health and Environment, Seoul National University, Seoul 08826, Republic of Korea \\ 2) Department of Preventive Medicine, College of Medicine, Seoul National University, Seoul 03080, Republic of Korea
}

\begin{abstract}
Obesity is a major risk factor for chronic diseases and arises from the interactions between environmental factors and multiple genes. Psychosocial stress may affect the risk for obesity, modifying food intake and choice. A recent study suggested regulator of G-protein signaling $6(R G S 6)$ as a novel candidate gene for obesity in terms of reward-related feeding under stress. In this study, we tried to verify the unidentified connection between $R G S 6$ and human obesity with psychosocial stress in a Korean population. A total of 1,462 adult subjects, who participated in the Korean Association Resource cohort project, were included for this analysis. Obesity-related traits including waist circumference, body mass index, and visceral adipose tissue were recorded. A total of 4 intronic SNPs for the RGS6 gene were used for this study. We found that interactions between SNP rs2239219 and psychosocial stress are significantly associated with abdominal obesity $(p=0.007)$. As risk allele of this SNP increased, prevalence of abdominal obesity under high-stress conditions gradually increased $(p=0.013)$. However, we found no SNPs-by-stress interaction effect on other adiposity phenotypes. This study suggests that RGS6 is closely linked to stress-induced abdominal obesity in Korean adults.
\end{abstract}

Key words: RGS6, Abdominal obesity, Stress, Gene-environmental interaction

OBESITY is a major risk factor for chronic diseases (i.e., diabetes, vascular disease, and some types of cancer), leading to disability and premature death [1]. Obesity results from an imbalance between energy intake and energy expenditure, which is influenced by multiple genes, environmental factors, and the interactions between them [1]. Many concerns have been expressed regarding genetic predisposition, for example FTO and $M C 4 R$, to links between obesity and energy intake in the form of protein, carbohydrate, and high-fat food [2-4]. A recent studies suggested the regulator of G-protein signaling 6 (RGS6) as a novel candidate gene for adiposity, affecting dietary intake of palatable energy-dense foods $[5,6]$.

Interestingly, psychosocial stress can stimulate a behavioral tendency to fat and fatty/sugary diets, thereby contributing to the development of obesity [7]. A preference for such foods as a means of reward

Submitted Sep. 20, 2016; Accepted Nov. 24, 2016 as EJ16-0438 Released online in J-STAGE as advance publication Jan. 13, 2017

Correspondence to: Kyoung-Bok Min, Department of Preventive Medicine, College of Medicine, Seoul National University, 103 Daehak-ro, Jongno-gu, Seoul, 03080, Republic of Korea.

E-mail:minkb@snu.ac.kr would subsequently attenuate distress, in which opioids are mediators of reward-related feeding [8].

Given the role of RGS6 as the R7 subfamily of regulators of RGS proteins, interplaying with opioid receptors, we hypothesized that RGS6 might function to promote obesity through its activity in association with reward-related feeding. We conducted RGS6 gene-by-stress interaction analysis for obesity-related traits, including waist circumference (WC), body mass index (BMI), and visceral adipose tissue (VAT) in a Korean population.

\section{Materials and Methods}

\section{Study samples}

The samples used for this study were obtained by the Korean Association Resource (KARE) cohort project, which is a consortium for the regional cohorts in Ansung and Ansan areas of Korea [9]. In this study, we selected 1,462 residents in the Ansan province with the requisite phenotypic characteristics for adiposity phenotypes and psychosocial stress levels (Table 1). This study was approved by the institutional review board of Seoul National University (approval number, E1502/001-012). 


\section{Phenotypes}

In order to analyze comprehensive adiposity phenotypes, we obtained the VAT value from computed tomography, as well as anthropometric data such as height, weight, and WC. BMI $\left(\mathrm{kg} / \mathrm{m}^{2}\right)$ was estimated by dividing the weight $(\mathrm{kg})$ by the height ${ }^{2}\left(\mathrm{~m}^{2}\right)$. In addition, we defined three obese groups as follows: the "overall obesity" group, which was categorized as individuals with a BMI $\geq 25 \mathrm{~kg} / \mathrm{m}^{2}$; the "abdominal obesity" group, which was categorized as individuals with $\mathrm{WC}$ for male $\geq 90 \mathrm{~cm}$ or $\mathrm{WC}$ for female $\geq 80 \mathrm{~cm}$; and the "visceral obesity" group, which was categorized as individuals with VAT $\geq 136 \mathrm{~cm}^{2}$ [10]. The number of subjects with "overall obesity", "abdominal obesity", and "visceral obesity" were 643, 349, and 101, respectively. The stress levels of subjects were assessed by a Psychosocial Well-being Index short form (PWI-SF) questionnaire, which is revised as Korean-translated version based on the Goldberg's General Health Questionnaire-60. This form includes a total of 18 questions (11 perceived well-being questions and 7 perceived distress questions). The score of each question ranged from 0 to 3, and total score is the sum of scores in each question. Higher scores in the perceived well-being items indicated higher levels of stress condition, whereas higher scores in perceived distress items such as discomfort, pain, and anxiety indicated lower levels of stress. Each subscale for distress questions was reverse calculated. Therefore, a higher total score reflects a higher level of stress. The subjects with a total PWI-SF score of more than 27 were defined as individuals under high levels of psychosocial stress.

\section{Genotyping}

The SNP data genotyped in the initial KARE project by Affymetrix genome-wide human SNP Array 5.0 were used for this study. Candidate SNPs for the $R G S 6$ gene were selected based on the previous report [6]. Of the 23 SNPs that were reported by the Sibbel et $a l$., a total of six SNP genotypes were included in the Affymetrix genome-wide human SNP Array 5.0 data. We assessed the pairwise LD relationship between these SNPs using Haploview software (version 4.2), and only the SNPs which were in low LD relationship (pairwise $r^{2}<0.5$ ) were included in final analyses. If the LD relationship between two SNPs was moderate or strong (pairwise $r^{2} \geq 0.5$ ), only SNP with a lower $p$-value in Sibbel's study were selected. As a result, two SNPs which were in moderate or high LD level
Table 1 Characteristics of study subjects

\begin{tabular}{lc}
\hline Characteristics & Mean (SD) or n (\%) \\
\hline Total $(\mathrm{n})$ & 1,462 \\
No. of females (\%) & $561(38.4)$ \\
Age (years) & $56.4(7.4)$ \\
BMI $\left(\mathrm{kg} / \mathrm{m}^{2}\right)$ & $24.6(2.9)$ \\
WC $(\mathrm{cm})$ & $80.8(7.8)$ \\
VAT $\left(\mathrm{cm}^{2}\right)$ & $79.3(36.1)$ \\
\hline Psychosocial stress (n (\%)) & $1,251(85.6)$ \\
$\quad$ Low-to-moderate & $211(14.4)$ \\
\hline High &
\end{tabular}

BMI, body mass index; WC, waist circumference; VAT, visceral adipose tissue.

Table 2 Pairwise linkage disequilibrium levels between four SNPs implemented in Haploview

\begin{tabular}{llll}
\hline SNP1 & \multicolumn{1}{c}{ SNP2 } & $\mathrm{D}^{\prime}$ & $\mathrm{R}^{2}$ \\
\hline rs2238199 & rs2681749 & 0.826 & 0.162 \\
rs2238199 & rs847330 & 0.821 & 0.047 \\
rs2238199 & rs2239219 & 0.268 & 0.055 \\
rs2681749 & rs847330 & 0.978 & 0.277 \\
rs2681749 & rs2239219 & 0.594 & 0.064 \\
rs847330 & rs2239219 & 0.902 & 0.043 \\
\hline
\end{tabular}

SNP, single nucleotide polymorphism.

were deleted, and a total of four SNPs were finally included in the analyses. The detailed information about pairwise LD level of these SNPs was indicated in Table 2. The call rates for these SNPs ranged from $98.6 \%$ to $100 \%$.

\section{Statistical analysis}

Before analyses, all phenotypes were transformed by a square root to meet the normality assumption. We also assessed Hardy-Weinberg equilibrium (HWE) and ascertained that all four SNPs had passed the HWE threshold (all $p>0.05$ ). To identify RGS6 gene-by-stress interaction effects as well as the SNP association on obesity, we performed multiple linear or logistic regression analyses with PLINK software (version 1.9). These results were adjusted using covariates such as age and sex under assumption of additive genetic model. The main effects of the SNPs were tested with the SNP-only model without stress and interaction term $\left(Y=\beta_{0}+\beta_{1}\right.$ age $+\beta_{2}$ sex $\left.+\beta_{3} S N P_{A D D}+e\right)$. The interaction tests of the SNPs and stress were performed on the multiple regression model with stress and interaction term $\left(Y=\beta_{0}+\beta_{1}\right.$ age $+\beta_{2}$ sex $+\beta_{3} S N P_{A D D}+$ $\beta_{4}$ stress $+\beta_{5} S N P_{A D D} x$ stress $\left.+e\right)$. We assessed statistical significance with Bonferroni correction using the number of SNPs tested in this study $(0.05 / 4=0.0125)$. However, Bonferroni correction was not performed for the number of traits given that the obesity-related traits 
were considerably inter-correlated $\left(\mathrm{r}_{\text {corr }}=0.64-0.81\right.$, all $\left.p_{\text {corr }}<0.0001\right)$.

\section{Results}

A total of 1,462 subjects were finally included for this study. The proportion of male subjects $(61.6 \%)$ was higher than female (38.4\%), and the mean age of the study subjects was 56.4 years. The mean values of BMI $\left(\mathrm{kg} / \mathrm{m}^{2}\right)$, WC $(\mathrm{cm})$, and VAT $\left(\mathrm{cm}^{2}\right)$ were 24.6 , 80.8 , and 79.3 , respectively. Out of the total sample, $211(14.4 \%)$ subjects showed extremely high stress levels (Table 1).

Table 3 indicates the multiple logistic regression results for obesity-related quantitative traits. In only SNP model results without stress and SNP $\mathrm{x}$ stress level terms, two SNPs (rs2238199 and rs2681749) had nominal associations with at least one obesity-related phenotype. In particular, rs2238199 showed statistically significant associations with BMI $(p=0.009)$, but its interaction effect was not significant $\left(p_{\text {int }}=0.521\right)$. The SNP rs2239219 was nominally associated with WC by interacting with stress $\left(p_{\text {int }}=0.029\right)$.

The main and interaction results for binary traits (e.g. case control status) are shown in Table 4. The SNP rs2238199 that showed a significant association with BMI had a nominal association with overall obesity $(p=0.019)$. In addition to this SNP, we found no significant genetic main effect between RGS6 SNPs and obesity groups (all $p>0.05$ ). On the other hand, other three SNPs (rs2681749, rs847330, and rs2239219) except for rs2238199 showed nominal interaction effects with abdominal obesity. Of these, one SNP rs2239219 showed statistically significant interaction with abdominal obesity, reaching our significant level of $p_{\text {int }}<0.0125$. A full model result for this SNP in abdominal obesity is indicated in Supplementary Table 1. However, we found no SNPs-by-stress interaction effect on other adiposity phenotypes except for abdominal obesity.

Table 3 Interaction results of RGS6 SNPs and stress level for obesity-related quantitative traits

\begin{tabular}{|c|c|c|c|c|c|c|c|c|c|c|c|c|c|}
\hline \multirow{3}{*}{ SNP } & \multirow{3}{*}{ MAF } & \multicolumn{4}{|c|}{$\mathrm{BMI}\left(\mathrm{kg} / \mathrm{m}^{2}\right)$} & \multicolumn{4}{|c|}{ WC $(\mathrm{cm})$} & \multicolumn{4}{|c|}{$\operatorname{VAT}\left(\mathrm{cm}^{2}\right)$} \\
\hline & & \multicolumn{2}{|c|}{ Main } & \multicolumn{2}{|c|}{ Interaction } & \multicolumn{2}{|c|}{ Main } & \multicolumn{2}{|c|}{ Interaction } & \multicolumn{2}{|c|}{ Main } & \multicolumn{2}{|c|}{ Interaction } \\
\hline & & $\begin{array}{l}\beta_{\mathrm{SNP}} \\
(\mathrm{SE})\end{array}$ & $p_{\mathrm{SNP}}$ & $\begin{array}{c}\beta_{\text {int }} \\
(\mathrm{SE})\end{array}$ & $p_{\text {int }}$ & $\begin{array}{l}\beta_{\mathrm{SNP}} \\
(\mathrm{SE})\end{array}$ & $p_{\mathrm{SNP}}$ & $\begin{array}{c}\beta_{\text {int }} \\
(\mathrm{SE})\end{array}$ & $p_{\text {int }}$ & $\begin{array}{l}\beta_{\mathrm{SNP}} \\
(\mathrm{SE})\end{array}$ & $p_{\mathrm{SNP}}$ & $\begin{array}{l}\beta_{\text {int }} \\
(\mathrm{SE})\end{array}$ & $p_{\text {int }}$ \\
\hline rs2238199 & 0.36 & $\begin{array}{c}0.029 \\
(0.011)\end{array}$ & $0.009^{\mathrm{a}}$ & $\begin{array}{c}0.019 \\
(0.030)\end{array}$ & 0.521 & $\begin{array}{c}0.035 \\
(0.016)\end{array}$ & 0.027 & $\begin{array}{c}0.022 \\
(0.043)\end{array}$ & 0.613 & $\begin{array}{c}0.131 \\
(0.076)\end{array}$ & 0.085 & $\begin{array}{c}0.347 \\
(0.206)\end{array}$ & 0.092 \\
\hline rs2681749 & 0.30 & $\begin{array}{l}-0.026 \\
(0.012)\end{array}$ & 0.027 & $\begin{array}{l}-0.039 \\
(0.031)\end{array}$ & 0.207 & $\begin{array}{l}-0.040 \\
(0.017)\end{array}$ & 0.015 & $\begin{array}{l}-0.072 \\
(0.044)\end{array}$ & 0.104 & $\begin{array}{l}-0.190 \\
(0.080)\end{array}$ & 0.017 & $\begin{array}{l}-0.290 \\
(0.212)\end{array}$ & 0.173 \\
\hline rs847330 & 0.11 & $\begin{array}{l}-0.013 \\
(0.017)\end{array}$ & 0.437 & $\begin{array}{l}-0.030 \\
(0.043)\end{array}$ & 0.487 & $\begin{array}{l}-0.017 \\
(0.024)\end{array}$ & 0.489 & $\begin{array}{l}-0.092 \\
(0.061)\end{array}$ & 0.130 & $\begin{array}{l}-0.084 \\
(0.116)\end{array}$ & 0.468 & $\begin{array}{l}-0.420 \\
(0.293)\end{array}$ & 0.152 \\
\hline rs2239219 & 0.30 & $\begin{array}{c}0.008 \\
(0.012)\end{array}$ & 0.508 & $\begin{array}{c}0.021 \\
(0.035)\end{array}$ & 0.546 & $\begin{array}{c}0.007 \\
(0.017)\end{array}$ & 0.670 & $\begin{array}{c}0.109 \\
(0.050)\end{array}$ & 0.029 & $\begin{array}{c}0.043 \\
(0.082)\end{array}$ & 0.602 & $\begin{array}{c}0.418 \\
(0.243)\end{array}$ & 0.086 \\
\hline
\end{tabular}

BMI, body mass index; WC, waist circumference; VAT, visceral adipose tissue; SNP, single nucleotide polymorphism; MAF, minor allele frequency; SE, standard error. The estimates for main $\left(\beta_{\mathrm{SNP}}(\mathrm{SE})\right.$ and $\left.P_{\mathrm{SNP}}\right)$ are results of the SNP-only model including age, sex, and SNP without stress and interaction term. The estimates for interaction $\left(\beta_{\text {int }}(\mathrm{SE})\right.$ and $\left.P_{\text {int }}\right)$ are results of the interaction effect in the multiple regression model including age, sex, SNP, stress, and SNP x stress. Nominally significant $p$ values are marked in bold $(p<0.05)$. ${ }^{a} p$ value meets the Bonferroni multiple correction threshold of $p=0.0125(0.05 / \# \mathrm{SNPs}=4)$.

Table 4 Interaction results of RGS6 SNPs and stress level for obesity-related binary traits

\begin{tabular}{|c|c|c|c|c|c|c|c|c|c|c|c|c|}
\hline \multirow{3}{*}{ SNP } & \multicolumn{4}{|c|}{ Overall obesity $(\mathrm{n}=643)$} & \multicolumn{4}{|c|}{ Abdominal obesity $(\mathrm{n}=349)$} & \multicolumn{4}{|c|}{ Visceral obesity $(\mathrm{n}=101)$} \\
\hline & \multicolumn{2}{|c|}{ Main } & \multicolumn{2}{|c|}{ Interaction } & \multicolumn{2}{|c|}{ Main } & \multicolumn{2}{|c|}{ Interaction } & \multicolumn{2}{|c|}{ Main } & \multicolumn{2}{|c|}{ Interaction } \\
\hline & $\begin{array}{c}\mathrm{OR}_{\mathrm{SNP}} \\
(95 \% \mathrm{CI})\end{array}$ & $p_{\mathrm{SNP}}$ & $\begin{array}{c}\mathrm{OR}_{\text {int }} \\
(95 \% \mathrm{CI})\end{array}$ & $p_{\text {int }}$ & $\begin{array}{c}\mathrm{OR}_{\mathrm{SNP}} \\
(95 \% \mathrm{CI})\end{array}$ & $p_{\mathrm{SNP}}$ & $\begin{array}{c}\mathrm{OR}_{\text {int }} \\
(95 \% \mathrm{CI})\end{array}$ & $p_{\text {int }}$ & $\begin{array}{c}\mathrm{OR}_{\mathrm{SNP}} \\
(95 \% \mathrm{CI})\end{array}$ & $p_{\mathrm{SNP}}$ & $\begin{array}{c}\mathrm{OR}_{\text {int }} \\
(95 \% \mathrm{CI})\end{array}$ & $p_{\text {int }}$ \\
\hline $\mathrm{rs} 2238199$ & $\begin{array}{c}1.20 \\
(1.03-1.39)\end{array}$ & 0.019 & $\begin{array}{c}1.29 \\
(0.85-2.0)\end{array}$ & 0.233 & $\begin{array}{c}1.19 \\
(0.99-1.43)\end{array}$ & 0.055 & $\begin{array}{c}1.38 \\
(0.85-2.24)\end{array}$ & 0.194 & $\begin{array}{c}1.28 \\
(0.95-1.71)\end{array}$ & 0.103 & $\begin{array}{c}1.31 \\
(0.61-2.82)\end{array}$ & 0.489 \\
\hline rs2681749 & $\begin{array}{c}0.90 \\
(0.77-1.06)\end{array}$ & 0.202 & $\begin{array}{c}0.67 \\
(0.44-1.07)\end{array}$ & 0.094 & $\begin{array}{c}0.91 \\
(0.75-1.11)\end{array}$ & 0.355 & $\begin{array}{c}0.57 \\
(0.33-0.97)\end{array}$ & 0.040 & $\begin{array}{c}0.76 \\
(0.54-1.05)\end{array}$ & 0.099 & $\begin{array}{c}0.64 \\
(0.24-1.65)\end{array}$ & 0.353 \\
\hline rs847330 & $\begin{array}{c}0.89 \\
(0.70-1.12)\end{array}$ & 0.310 & $\begin{array}{c}0.74 \\
(0.40-1.37)\end{array}$ & 0.340 & $\begin{array}{c}0.93 \\
(0.70-1.24)\end{array}$ & 0.624 & $\begin{array}{c}0.37 \\
(0.15-0.91)\end{array}$ & 0.030 & $\begin{array}{c}0.93 \\
(0.58-1.49)\end{array}$ & 0.760 & $\begin{array}{c}0.21 \\
(0.03-1.54)\end{array}$ & 0.124 \\
\hline rs2239219 & $\begin{array}{c}1.05 \\
(0.89-1.23)\end{array}$ & 0.577 & $\begin{array}{c}1.19 \\
(0.73-1.93)\end{array}$ & 0.495 & $\begin{array}{c}1.05 \\
(0.86-1.28)\end{array}$ & 0.636 & $\begin{array}{c}2.21 \\
(1.24-3.92)\end{array}$ & $0.007^{\mathrm{a}}$ & $\begin{array}{c}1.11 \\
(0.80-1.53)\end{array}$ & 0.527 & $\begin{array}{c}1.66 \\
(0.69-4.00)\end{array}$ & 0.261 \\
\hline
\end{tabular}

SNP, single nucleotide polymorphism; OR, odds ratio; CI, confidence interval. The estimates for main $\left(\mathrm{OR}_{\mathrm{SNP}}(95 \% \mathrm{CI})\right.$ and $\left.P_{\mathrm{SNP}}\right)$ are results of the SNP-only model including age, sex, and SNP without stress and interaction term. The estimates for interaction $\left(\mathrm{OR}_{\mathrm{int}}\right.$ $(95 \% \mathrm{CI})$ and $\left.P_{\text {int }}\right)$ are results of the interaction effect in the multiple regression model including age, sex, SNP, stress, and SNP x stress. Nominally significant $p$ values are marked in bold $(p<0.05)$. ${ }^{a} p$ value meets the Bonferroni multiple correction threshold of $p=0.0125$ (0.05/\#SNPs=4). 
We compared the prevalence of abdominal obesity according to the psychosocial stress and genotype of the significant SNP rs2239219 (Fig. 1). The prevalence of abdominal obesity (38.46\%) in homozygous risk allele carriers who were living under highly stressful conditions was much higher, compared to those of the low to moderate stress level (rs2239219 $=14.61 \%$ increase). This SNP was significantly associated with the prevalence of abdominal obesity in high stress group ( $p<$ 0.05 ), whereas significant association in low-moderate stress group was not observed $(p>0.05)$.

\section{Discussion}

This study aimed to investigate interaction effects of $R G S 6$ SNPs-by-psychosocial stress for obesity-related phenotypes to understand the link between $R G S 6$ and obesity. We identified that interaction between SNP rs2239219 and stress is significantly associated with abdominal obesity $\left(p_{\text {int }}=0.007\right)$. As the risk allele of these SNPs increased, the prevalence of abdominal obesity under high stress conditions gradually increased ( $p$ $=0.013$ ). These results support the biological hypothesis of $R G S 6$ that an opioid system modulated by RGS6 under chronic stress influences the intake of palatable foods, thereby leading to human obesity.

The prevalence of the "subjects who showed extremely high stress levels" in this study was $14.4 \%$, and this figure was comparable to that of Korean general population. In 2014, Kye and park's study based on the population-based database using multiple strat- ified random sampling on the Korea Census of 2005 reported that the prevalence of high stress (PWI-SF $\geq 27$ ) was $16.5 \%$ [11]. In addition, Yoon et al. in 2015 performed the large-scale epidemiological study regarding sleep duration with 84,094 Korean subjects aged 40-69 [12]. According to their report, the prevalence of severe distress (PWI-SF $\geq 27$ ) in total sample was $13.7 \%$, and prevalence in women $(15.6 \%)$ was higher than that of men $(9.9 \%)$. In our data, difference of prevalence between men and women was also observed, indicating a higher prevalence in women $(18.0 \%)$ than that in men (12.2\%) (Data not shown). This consistent result may be critical to apply our significant findings to Korean general population. RGS6 belongs to the R7 subfamily of RGS (regulator of G-protein signaling) family, which is widely expressed in multiple tissues including ovarian, bladder, and brain $[13,14]$. In particular, in tissues of the central nervous system such as the spinal cord and pons-medulla, $R G S 6$ shows the highest mRNA expression levels [14]. This gene plays an important role in signaling by opioid effects which involves a negative feedback mechanism, acting downstream of opioid receptors to produce tachyphylaxis and acute tolerance [14]. Severe psychosocial stress causes an elevated cortisol level and it promotes consumption of sweet, fatty, and calorie-dense "comfort food". This eventually gives rise to opioid release, not only to control mechanisms activated during the prolonged stress response, but also to inhibit further cortisol secretion $[6,15]$. Thus, it is plausible that SNPs within

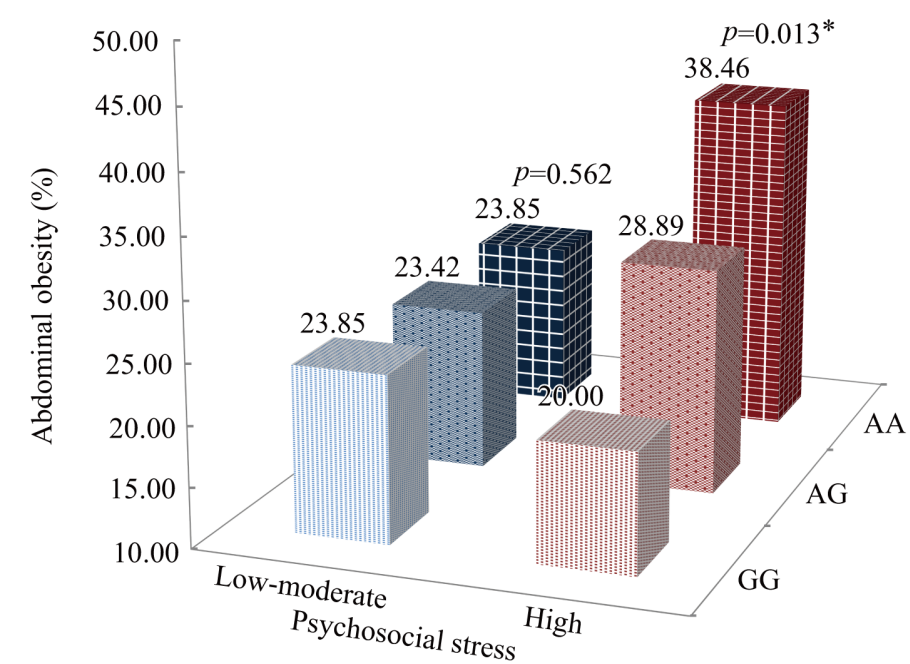

Fig. 1 The prevalence of abdominal obesity (WC for male $\geq 90 \mathrm{~cm}$ or $\mathrm{WC}$ for female $\geq 80 \mathrm{~cm}$ ) according to psychosocial stress level and a SNP rs2239219 genotypes $(* p<0.05)$ 
$R G S 6$ alter the function of the gene, and this has an influence on the opioid system for negative feedback under stress response. However, additional studies for non-synonymous coding SNPs are needed to achieve functionality of RGS6 in stress-induced obesity.

Few studies regarding $R G S 6$ gene and obesity have been reported. In 2009, Norris et al.'s study first identified the significant association between RGS6 polymorphisms and the distribution of adiposity [5]. In 2012 , they verified their hypothesis that $R G S 6$ is closely related with adiposity through increased preference towards fat-laden food intake [6]. Recently, a genetic study in Korean men failed to replicate the association between three RGS6 SNPs (rs847354, rs7147236, and rs6574069) and adiposity traits [10]. However, our results showed that two SNPs (rs2238199 and rs2681749) were nominally associated with obesity-related traits such as BMI, WC, and VAT. Although study populations of these two studies have a same racial background, these inconsistent results may be explained by differences in types or characteristics of study samples, sex difference, and inconsistency of $R G S 6$ polymorphisms.

To date, many studies have identified a close relationship between stress, eating behaviors, and the development of obesity. Most experimental results from animal models have provided evidence that stress leads to weight loss through reduced appetite or food intake $[16,17]$. By contrast, in humans, some people tend to eat less when stressed, whereas others eat more. During stressful periods, approximately $80 \%$ of people indicated changes in feeding behavior, and half of them demonstrated an increased food intake response [18]. In addition, one study reported that stress eaters during exam periods showed increases in cortisol, insulin, and lipid levels as, well as weight [19]. Notably, both animal and human studies have reported that stress can cause changes in food selection towards sugar- and fat-laden "palatable food", independently of hypophagia or hyperphagia [20,21]. This can be explained to some extent by the activation of brain reward systems. In 2007, Adam et al. proposed a reward model in stress eating, emphasizing the role of reward circuitry and cortisol on promoting highly palatable food intake [22]. In addition, a preferential shift towards "palatable food" eating is associated with food addiction, thereby leading to the development of obesity. Despite the absence of active stress, stress eating can stimulate habit-driven "palatable food" intake by enhancing pleasure and memories related with high-fat and sugary food consumption. We propose $R G S 6$ as one of crucial candidate genes for understanding epidemiological relations between stress eating, "palatable food" intake, and abdominal obesity based on the results reported by Sibbel et al.'s study [6]. However, replication study needs to confirm the causality between stress, RGS6, and abdominal obesity.

In present study, RGS6 SNPs-by-stress interaction effect was significantly associated with only abdominal obesity. In fact, studies have reported the associations between stress and abdominal or visceral obesity, rather than overall obesity. Our result shows the importance of gene-by-stress interaction on the development of abdominal obesity, although we did not identify the significant interaction effect for visceral obesity. Visceral fat was differently distributed by sex, but we could not perform sex-specific analysis on visceral obesity because of small sample size. Further gene-environmental interaction studies, conducted on large scale, are needed to determine the sex-specific effects on visceral obesity.

In summary, this study was to investigate a connection between $R G S 6$ and obesity with psychosocial stress level. We suggest for the first time that SNP rs2239219 of $R G S 6$ is closely linked to stress-induced abdominal obesity, emphasizing the importance of stress management on prevention of obesity in Korean adults.

\section{Acknowledgements}

This study was provided with biospecimens and data from the Korean Genome Analysis Project (4845301), the Korean Genome and Epidemiology Study (4851-302), and Korea Biobank Project (4851-307, KBP-2015-019) that were supported by the Korean Center for Disease Control and Prevention, Republic of Korea. This work was supported by the Basic Science Research Program through the National Research Foundation of Korea (NRF) funded by the Ministry of Education, Science and Technology (grant no. 2015R1A1A3A04000923，2015R1D1A1A01057619, and 2015R1D1A1A01059048). This work was supported by the Education and Research Encouragement Fund of Seoul National University Hospital (2016).

\section{Disclosure}

The authors declared no conflict of interest. 
Supplementary Table 1 The full model interaction results for rs2239219 in waist circumference and abdominal obesity

\begin{tabular}{|c|c|c|c|c|c|c|}
\hline \multirow{2}{*}{ Variables } & \multicolumn{3}{|c|}{ WC } & \multicolumn{3}{|c|}{ Abdominal obesity } \\
\hline & $\beta_{\text {int }}$ & SE & $p_{\text {int }}$ & $\mathrm{OR}_{\text {int }}$ & $95 \% \mathrm{CI}$ & $p_{\text {int }}$ \\
\hline Age & 0.008 & 0.001 & $<0.0001$ & 1.03 & $1.02-1.05$ & $<0.0001$ \\
\hline Sex & -0.273 & 0.022 & $<0.0001$ & 3.48 & $2.70-4.50$ & $<0.0001$ \\
\hline Stress & -0.098 & 0.042 & 0.020 & 0.60 & $0.36-1.00$ & 0.048 \\
\hline rs2239219 & -0.117 & 0.059 & 0.048 & 0.43 & $0.21-0.84$ & 0.014 \\
\hline Stress*rs2239219 & 0.109 & 0.050 & 0.029 & 2.21 & $1.24-3.92$ & 0.007 \\
\hline
\end{tabular}

WC, waist circumference; SE, standard error; OR, odds ratio; CI, confidence interval.

\section{References}

1. Yang W, Kelly T, He J (2007) Genetic epidemiology of obesity. Epidemiol Rev 29: 49-61.

2. Cecil JE, Tavendale R, Watt P, Hetherington MM, Palmer CN (2008) An obesity-associated FTO gene variant and increased energy intake in children. $N$ Engl J Med 359: 2558-2566.

3. Pichler M, Kollerits B, Heid IM, Hunt SC, Adams TD, et al. (2008) Association of the melanocortin-4 receptor V103I polymorphism with dietary intake in severely obese persons. Am J Clin Nutr 88: 797-800.

4. Speakman JR, Rance KA, Johnstone AM (2008) Polymorphisms of the FTO gene are associated with variation in energy intake, but not energy expenditure. Obesity (Silver Spring) 16: 1961-1965.

5. Norris JM, Langefeld CD, Talbert ME, Wing MR, Haritunians T, et al. (2009) Genome-wide association study and follow-up analysis of adiposity traits in Hispanic Americans: the IRAS Family Study. Obesity (Silver Spring) 17: 1932-1941.

6. Sibbel SP, Talbert ME, Bowden DW, Haffner SM, Taylor KD, et al. (2011) RGS6 Variants Are Associated With Dietary Fat Intake in Hispanics: The IRAS Family Study. Obesity (Silver Spring) 19: 1433-1438.

7. Sominsky L, Spencer SJ (2014) Eating behavior and stress: a pathway to obesity. Front Psychol 5: 434.

8. Levine AS, Billington CJ (2004) Opioids as agents of reward-related feeding: a consideration of the evidence. Physiol Behav 82: 57-61.

9. Cho YS, Go MJ, Kim YJ, Heo JY, Oh JH, et al. (2009) A large-scale genome-wide association study of Asian populations uncovers genetic factors influencing eight quantitative traits. Nat Genet 41: 527-534.

10. Kim HJ, Park JH, Lee S, Son HY, Hwang J, et al. (2015) A Common Variant of NGEF Is Associated with Abdominal Visceral Fat in Korean Men. PLoS One 10: e0137564.

11. Kye SY, Park K (2014) Health-related determinants of happiness in Korean adults. Int J Public Health 59:
731-738.

12. Yoon HS, Yang JJ, Song M, Lee HW, Han S, et al. (2015) Correlates of self-reported sleep duration in middle-aged and elderly Koreans: from the Health Examinees Study. PLoS One 10: e0123510.

13. Berman DM, Wang YF, Liu ZY, Dong Q, Burke LA, et al. (2004) A functional polymorphism in RGS6 modulates the risk of bladder cancer. Cancer Res 64: 6820-6826.

14. Lopez-Fando A, Rodriguez-Munoz M, SanchezBlazquez P, Garzon J (2005) Expression of neural RGSR7 and Gbeta5 Proteins in Response to Acute and Chronic Morphine. Neuropsychopharmacology 30: 99-110.

15. Drolet G, Dumont EC, Gosselin I, Kinkead R, Laforest S, et al. (2001) Role of endogenous opioid system in the regulation of the stress response. Prog Neuropsychopharmacol Biol Psychiatry 25: 729-741.

16. Carr JA (2002) Stress, neuropeptides, and feeding behavior: A comparative perspective. Integr Comp Biol 42: $582-590$.

17. Levine AS, Morley JE (1981) Stress-Induced Eating in Rats. Am J Physiol 241: R72-R76.

18. Dallman MF (2010) Stress-induced obesity and the emotional nervous system. Trends Endocrinol Metab 21: 159-165.

19. Epel E, Jimenez S, Brownell K, Stroud L, Stoney C, et al. (2004) Are stress eaters at risk for the metabolic syndrome? Ann N Y Acad Sci 1032: 208-210.

20. Pecoraro N, Reyes F, Gomez F, Bhargava A, Dallman MF (2004) Chronic stress promotes palatable feeding, which reduces signs of stress: feedforward and feedback effects of chronic stress. Endocrinology 145: 3754-3762

21. Zellner DA, Loaiza S, Gonzalez Z, Pita J, Morales J, et al. (2006) Food selection changes under stress. Physiol Behav 87: 789-793.

22. Adam TC, Epel ES (2007) Stress, eating and the reward system. Physiol Behav 91: 449-458. 